\title{
Análisis multitemporal del urbanismo expansivo en el corredor del Henares. Aportación de las imágenes de satélite ${ }^{1}$
}

\section{Analysis of urban expansion in the "Corredor del Henares». The contribution of satellite images}

\author{
María Pilar García Rodríguez y María Eugenia Pérez González²
}

\section{ANTECEDENTES}

El sellado de suelos por causas antrópicas es uno de los problemas ambientales más importantes en Europa, en gran parte debido a la expansión urbana, industrial y turística, y a una inadecuada ordenación del territorio (Blum, 1998; Lavalle et al., Proyecto Moland, 2001 y AEMA, 2006).

La propuesta española para la estrategia UE 2020 para un desarrollo sostenible establece como objetivo prioritario proteger y mejorar los suelos de la Unión Europea con especial énfasis en el sellado del suelo (http://www.eeb. org/press/2009) y tratar los procesos de degradación causados por prácticas insostenibles en su utilización.

En toda Europa el cambio más importante en el uso del suelo es el debido al incremento de la edificación y obras públicas (Blum et al., 2004; Van-Camp

\footnotetext{
${ }^{1}$ Este artículo se enmarca dentro del Proyecto "Sellado de suelo en la Comunidad de Madrid y áreas limítrofes. Estudio mediante Teledetección y Sistemas de Información Geográfica". CSO2012-34785. Ministerio de Economía y Competitividad, Gobierno de España.

${ }^{2}$ Departamento Análisis Geográfico Regional y Geografía Física, Universidad Complutense de Madrid. c/ Profesor Aranguren s/n.28040 Madrid. mpgarcia@ucm.es; meperez@ucm.es. Tf: 913945969 ; Fax: 913945963.
} 
et al., 2004 y Montanarella, 2007). El problema del sellado afecta especialmente a España en las áreas costeras y en las proximidades de las grandes ciudades (Castillo et al., 2004; García y Pérez, 2007; Moreira, 2012). El gran desarrollo urbanístico entre 1990 y 2007 es el responsable de que el sellado sea la mayor causa de degradación de suelos en España.

Por sellado de suelos «se entiende la acción de cubrir de forma permanente una superficie de relleno con material impermeable artificial, como cemento o asfalto», (Comisión Europea, 2012). Este proceso afecta principalmente a las grandes áreas urbanas y metropolitanas en las que amplias superficies de terreno han sido selladas debido a la urbanización y a la construcción de infraestructuras (carreteras, aeropuertos, ferrocarriles, puertos, etc.). El sellado del suelo tiene como efectos negativos irreversibles la impermeabilización del terreno y la modificación de los ecosistemas, alterando las funciones ecológicas del suelo y los flujos de materia y energía.

El notable crecimiento urbanístico a partir de los años noventa del pasado siglo ha intensificado este problema medioambiental en áreas alejadas de las grandes ciudades, pero bien comunicadas con ellas y que todavía disfrutan de menor precio del terreno e impuestos menos elevados. Son espacios de intenso crecimiento urbano por el denominado «efecto frontera», que afecta a las provincias limítrofes de ciudades relevantes (Estébanez, 1980; Méndez y Razquin, 1992; Bruinsma y Rietveld, 1993; Helliwell y Verdier, 2001; Feria Toribio, 2004; Solís, 2008; Spies, 2010, etc.). Una de las expansiones urbanísticas pioneras y más notables en España se ha producido entre Madrid y Guadalajara, con gran expansión del suelo urbano, industrial e infraestructuras viarias.

Con frecuencia los desarrollos urbanísticos han priorizado los criterios de viabilidad y rentabilidad económica en detrimento de los medioambientales. En épocas de gran retroceso de actividades agrícolas, ganaderas y forestales la planificación urbana apenas ha atendido a la calidad de los suelos, con un notable sellado de aquéllos de alta o media calidad. La crisis actual ha dejado numerosas promociones urbanísticas sin terminar, «fantasmas», y otras muchas no ocupadas, que dejan en evidencia las previsiones cortoplacistas y meramente especulativas.

En este trabajo se propone una metodología de seguimiento y evaluación del sellado de suelo a partir de imágenes de satélite, disponibles para cualquier país y con una continua actualización de la información espacial no dependiente de las administraciones locales. Estas técnicas de seguimiento del territorio deberían ser incorporadas por las administraciones competentes. 
Se ha seleccionado un sector del centro peninsular español muy dinámico desde el punto de vista urbanístico, que ha experimentado un notable incremento del sellado en los últimos treinta años. La teledetección permite localizar las áreas selladas y hacer un seguimiento continuado de los cambios acaecidos, si bien, en ocasiones, es complicado delimitar con exactitud su extensión salvo que se disponga de imágenes de alta resolución espacial. Este inconveniente se trata de paliar con la información obtenida de fotografías aéreas de gran escala (facilitadas en España por el Instituto Geográfico Nacional) y verificación de la verdad terreno. No obstante, la menor resolución temporal de los vuelos fotogramétricos frente a la actualización constante de imágenes satelitales nos anima a realizar propuestas de detección de sellado de suelos mediante tratamiento de imágenes de satélite.

La cartografía del sellado a través de imágenes no siempre es sencilla debido a la heterogeneidad de las superficies construidas, muchas veces mezcladas con espacios naturales, y a las diferentes características de las construcciones: viviendas uni y plurifamiliares, naves industriales, vías de comunicación, áreas de recreo, etc. Numerosos autores han tratado de solucionar este problema proponiendo distintos métodos de análisis (Ridd, 1995; Effland y Pouyat, 1997; Nizeyimana et al., 2001; Wu, 2004; Añó et al., 2005; Moeller, 2005; Kampouraki et al., 2006; García y Pérez, 2007; Sánchez et al., 2009; Scalenghe. y Ajmone-Marsan, 2009; Tomás et al., 2010; Escudero et al., 2010; García y Pérez, 2011), si bien el resultado varía mucho dependiendo de la precisión requerida y del ámbito de estudio.

\section{OBjetivos}

Los objetivos del trabajo se sintetizan en los siguientes puntos:

- Utilizar la teledetección en el análisis y seguimiento del sellado de suelos

- Identificar los mejores canales espectrales de distintos sensores para detectar el sellado de suelos

- Seleccionar las mejoras digitales que discriminan mejor los distintos tipos de sellado

- Evaluar la superficie sellada a partir de la clasificación supervisada a partir de la imagen obtenida con la mejora espectral más adecuada

- Comparar la clasificación con la verdad terreno

- Calcular el porcentaje de suelos sellados

- Determinar qué tipos de suelos están afectados por el proceso de impermeabilización 
Por tanto, a partir de los objetivos enumerados, el objetivo principal del trabajo es conocer los diferentes tipos de sellado, separando los que sí repercuten en el uso y disfrute de las personas (urbano, industrial, ocio, infraestructuras, etc.) y los que quedan en el paisaje como muestras del fracaso de la planificación urbana (obras sin finalizar o sin uso ni ocupación alguna, etc.). Además este trabajo tiene como principal finalidad conocer qué tipo de suelos se están perdiendo por sellado, para lo que se utilizará el mapa de suelos existente (Guerra y colaboradores, 1970), que las autoras han adaptado a la clasificación WRBSR de la FAO (2007).

\section{ÁREA DE ESTUDio}

El área de estudio se localiza entre las provincias de Guadalajara y Madrid: comprende parte de las comarcas de La Campiña, de la Alcarria y del «Corredor del Henares». Dada la proximidad a Madrid es la zona más poblada y desarrollada de toda la provincia de Guadalajara (figura 1). Geológicamente está constituida por materiales terciarios y cuaternarios que forman un característico relieve tabular con páramos calizos en la parte suroriental y materiales sedimentarios detríticos en la campiña, cortados por el río Henares con depósitos aluviales en su vega y materiales más heterogéneos y gruesos en sus terrazas. El predominio de amplias superficies llanas o con escasa pendiente en la campiña y terrazas del río Henares ha favorecido la expansión urbano-industrial de Madrid hacia Guadalajara desde finales de los años setenta del pasado siglo.

FIGURA 1

\section{ÁREA DE ESTUDIO}

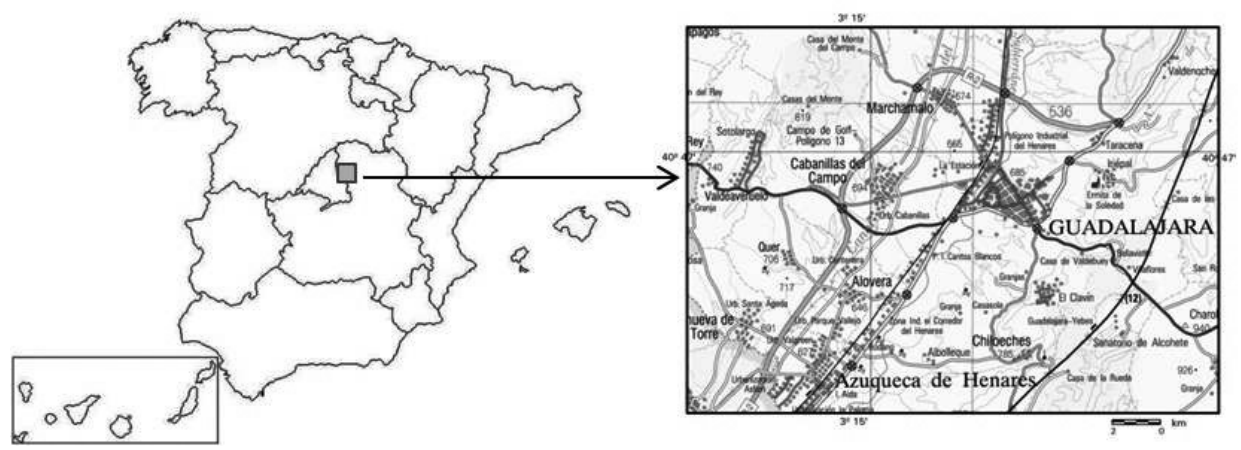

Estudios Geográficos, Vol. LXXV, 277, pp. 597-618, julio-diciembre 2014 ISSN: 0014-1496, eISSN: 1988-8546, doi: 10.3989/estgeogr.201419 
Los suelos constituyen asociaciones dominadas por cambisoles y luvisoles, con algunos planosoles en el noroeste, leptosoles en los páramos calizos y fluvisoles en las vegas de los ríos. La vegetación natural, repartida en manchas irregulares, está constituida por encinares y coscojares que, en muchos casos, han sido sustituidos por pinares de repoblación. Esta vegetación arbóreo-arbustiva predomina fundamentalmente en los frentes de los páramos y algunos enclaves del techo tabular. Cuando no ha sido sustituida por urbanizaciones esta vegetación ha experimentado un incremento considerable en su densidad, estabilizando algunos procesos erosivos en laderas. Siguiendo el curso de los ríos se desarrolla la vegetación higrófila. Parte de la campiña también conserva pequeñas extensiones de pastos y eriales.

El uso del suelo es fundamentalmente agrícola con cereales de secano, algunas parcelas de olivos, vides y frutales y, en las vegas, cultivos de regadío. Este uso tradicional típicamente mediterráneo convive con la intensa expansión urbana, industrial, recreativa y de vías de comunicación.

La gran transformación del espacio en los límites provinciales entre Madrid y Guadalajara queda reflejada en el importante incremento de población durante los últimos 30 años (44\%), responsable en gran medida del aumento del

TABLA 1

EVOLUCIÓN DE LA POBLACIÓN EN EL ÁREA DE ESTUDIO, INE

\begin{tabular}{lrrrrc}
\hline \multicolumn{1}{c}{ Municipios } & \multicolumn{1}{c}{1981} & \multicolumn{1}{c}{1991} & \multicolumn{1}{c}{2002} & \multicolumn{1}{c}{2011} & Difer. \% \\
\hline Alovera & 1.241 & 1.336 & 3.048 & 11.717 & 89,4 \\
Azuqueca & 9.789 & 11.624 & 21.185 & 34.195 & 71,4 \\
Cabanillas & 927 & 1.068 & 5.092 & 9.477 & 90,2 \\
Chiloeches & 941 & 1.066 & 1.481 & 3.077 & 69,4 \\
Guadalajara (capital) & 55.137 & 63.649 & 69.098 & 84.453 & 34,7 \\
Marchamalo & & & 4.337 & 6.042 & 71,8 \\
Quer & 88 & 110 & 88 & 661 & 86,7 \\
Torrejón del Rey & 438 & 437 & 1.544 & 5.041 & 91,3 \\
Valdeaveruelo & 102 & 158 & 434 & 1.052 & 90,3 \\
Total Provincia & 143.473 & 145.593 & 177.168 & 256.461 & 44,1 \\
Total munic. & 68.663 & 79.448 & 106.307 & 155.715 & 55,9 \\
\hline
\end{tabular}


sellado del suelo. Según los datos del Instituto Nacional de Estadística la población en la provincia de Guadalajara casi se ha duplicado en estos años, aunque si se consideran solo los municipios del área de estudio la población actual es más del doble de la censada en el año 1981, lo que indica que el incremento en la provincia se ha producido principalmente en el área más próxima a la Comunidad de Madrid. Caben destacar numerosos municipios de Guadalajara con aumentos poblacionales superiores al 70\% (gracias a los precios más asequibles) frente a la ciudad de Guadalajara que reduce el aumento de población al 34\%, valor muy alejado de los pequeños municipios que lo circundan (tabla 1). La ejecución de nuevas infraestructuras viarias, carreteras y autopistas, ha facilitado también el movimiento pendular de la población. No obstante, el desarrollo urbano apenas se ha realizado de momento a favor del tren de alta velocidad, cuya finalización más tardía y la desproporcionada previsión de la demanda de viviendas, ha dejado urbanizaciones sin terminar, «fantasmas» y altas pérdidas económicas.

\section{MATERIAL Y MÉTODOS}

El análisis del sellado de suelos se ha realizado principalmente a partir de las imágenes de los satélites Spot 5 y Landsat 5 y 7 de las escenas y fechas recogidas en la tabla 2. Estas imágenes se han obtenido a través del servidor de Internet de la Universidad de Maryland y USGS (http://glcf.umd.edu/) y del Plan Nacional de Teledetección de la Administración General del Estado y las Comunidades Autónomas, a través del Instituto Geográfico Nacional (ftp://ftp.pnt.ign.es/). La resolución de sus sensores, tanto espectral como espacial, es bastante adecuada para este tipo de estudios.

Las imágenes se han tratado con el programa Erdas Imagine 2011. Todas las imágenes están georreferidas y se han sometido a distintas mejoras (Chuvieco, 2000):

- Espaciales: filtros summary 5 × 5 y 3 × 3

- Espectrales: mezcla de bandas, componentes principales, transformación de las propiedades del color a colores primarios (de IHS a RVA), Índice de la Diferencia Normalizada de Vegetación (NDVI) y Tasseled Cap

- Radiométrica: ecualización del histograma

Con el fin conocer las diferentes tipologías de sellado (infraestructuras, urbano, residencial, industrial, etc.) se han fusionado las imágenes pancromática y multiespectral del satélite Spot. Esta mezcla de imágenes se realiza 
mediante el método de componentes principales y con un remuestreo aplicando la técnica de convolución cúbica.

No obstante para analizar la superficie sellada entre 1989 y 2011 deben utilizarse imágenes de satélites de diferente resolución espacial, pues los satélites y sensores de alta resolución son más recientes. Así el Spot 5, sensor HRG (High-Resolution Geometric), con 2,5 m de resolución espacial se lanza en 2002.

TABLA 2

IMÁGENES DE SATÉLITE UTILIZADAS

\begin{tabular}{llll}
\hline \multicolumn{1}{c}{ Satélite } & Sensor & \multicolumn{1}{c}{ Escena } & Fecha \\
\hline Landsat 5 & TM & $201-32$ & $25-03-1989$ \\
Landsat 7 & ETM + & $201-32$ & $22-04-2002$ \\
Landsat 5 & TM & $201-32$ & $26-06-2011$ \\
Spot 5 & HRG & 268-35 Multiespectral & $17-09-2011$ \\
& & 268-35 Pancromática & \\
\hline
\end{tabular}

El cálculo de la superficie total sellada se obtiene a partir de la clasificación supervisada de las imágenes en componentes principales, estableciendo dos categorías (sellada y no sellada) para las diferentes fechas (1989, 2002 y 2011). Esta clasificación se ha realizado con el criterio de mínima distancia, por el cual el píxel se asigna a la clase más cercana (Chuvieco, 2000).

Los mapas de sellado obtenidos mediante esta clasificación se han solapado con el mapa de suelos de Guerra y colaboradores (1970), con el fin de conocer el tipo de suelos que se ha perdido. Para ello se ha requerido adaptar la clasificación al sistema WRBSR de la FAO (2007) y georreferir el mapa a la proyección UTM, zona 30, con esferoide y datum WGS84.

Los resultados obtenidos han sido contrastados con la verdad terreno y con los mapas de ocupación de suelo de SIOSE y Corine Land Cover de la Agencia Europea del Medioambiente, la imagen del Google Earth y las fotografías aéreas de alta resolución espacial del programa PNOA del IGN. Dado que la clasificación del Corine Land Cover no ofrece una alta fiabilidad en algunas clases, constándose en la Comunidad de Madrid un error hasta del 68\% en clases complejas (Catalá et. al., 2008), se ha optado por comprobar en el 
campo la veracidad de la clasificación supervisada. En los puntos más conflictivos, que se dieron en residencias unifamiliares con espacios verdes, áreas recreativas y algunas naves industriales, una vez comprobada la verdad terreno, se ha realizado un remuestreo que ha mejorado la clasificación.

\section{RESULTADOS Y DISCUSIÓN}

Al comparar las imágenes de los distintos sensores y diferentes fechas lo primero que se observa es el gran incremento del sellado en la vega del río Henares y en las proximidades de la ciudad de Guadalajara, con un importante sellado también en las campiñas situadas en la margen derecha del río y en los páramos de la margen izquierda.

Un hecho significativo es que el sellado entre 1989 y 2002 es debido principalmente a la construcción de viviendas e infraestructuras todas ellas finalizadas. Sin embargo, entre 2002 y 2011 destaca la presencia de numerosas urbanizaciones «fantasmas», que han provocado el sellado de los suelos por el asfaltado de calles, pero con las parcelas sin construir. Esto implica un grave problema, pues la pérdida del ecosistema natural con los cambios que provoca la impermeabilización, no se ha visto compensado por mejoras en el ámbito socioeconómico.

\section{Análisis visual y digital de las imágenes Landsat y SPOT}

El primer paso para el análisis del sellado de suelos es conocer qué canales espectrales discriminan mejor las distintas cubiertas del suelo. Se trata de identificar tanto los diferentes tipos de edificaciones e infraestructuras, como la pérdida de las diferentes unidades de suelos y coberturas.

La alta resolución espectral de las imágenes Landsat TM y ETM+ permiten mezclar bandas con longitudes de ondas del espectro visible, infrarrojos próximos, medios y térmica, aunque su resolución espacial limita la identificación de superficies muy heterogéneas. Por esta razón, se han analizado también imágenes Spot del año 2011, pancromática y multiespectral, ya que su resolución espacial de 2,5 y 10 m respectivamente, consigue subsanar algunas de las limitaciones de las imágenes Landsat.

De las imágenes de los sensores TM y ETM+ el canal espectral que ofrece mejores resultados es el 1 o banda visible del azul (figura 2), ya que permite identificar los suelos sellados en tonos claros, si bien las infraestructuras no se 
distinguen muy nítidas. En las combinaciones de bandas las que mejor resaltan el sellado son aquéllas que incluyen los canales visibles e infrarrojos medios, no siendo útil el uso del infrarrojo próximo. Las mejores mezclas son: 5-2-1, 7-2-1, 1-1-5, 3-2-1 y 7-5-1. Debe destacarse que la óptima identificación del sellado, puede obtenerse con mezcla de tres bandas diferentes o mediante el uso de dos de ellas (1-1-5, 5-1-1 ó 1-5-1). En este caso la combinación de la banda azul con el canal infrarrojo medio resalta los suelos sellados, independientemente del cañón que se le asigne a cada banda, ya que resalta la humedad (o ausencia de ella) y la impermeabilización del suelo.

\section{FIGURA 2}

\section{BANDA 1 DE LOS SENSORES TM Y ETM+}

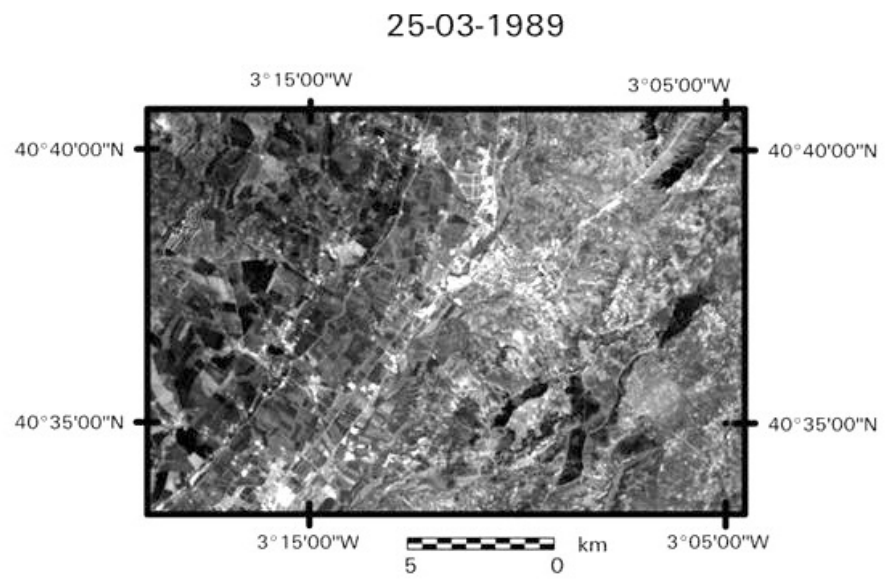

22-04-2002

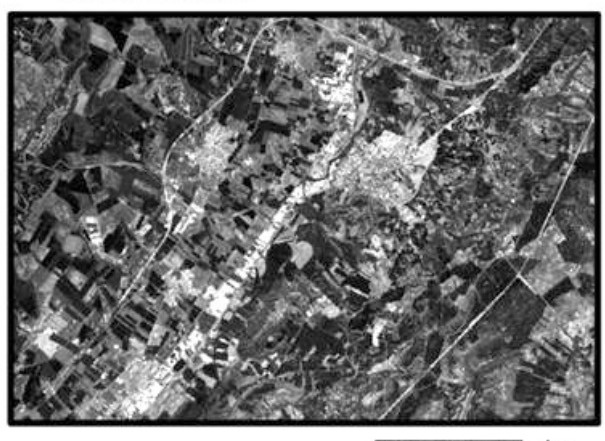

$\mathrm{r}=-\mathrm{m}=\mathrm{m} \mathrm{km}$
26-06-2011

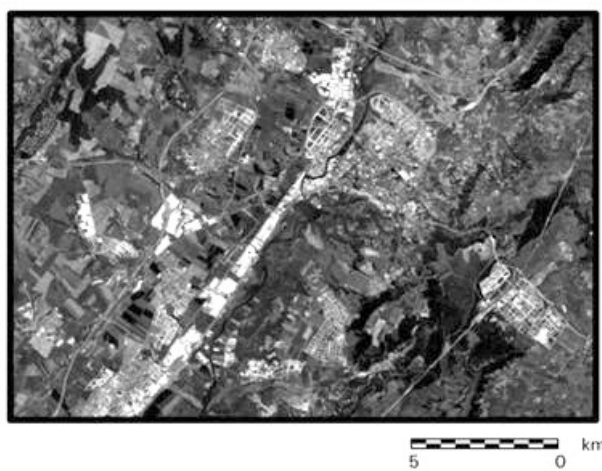

Estudios Geográficos, Vol. LXXV, 277, pp. 597-618, julio-diciembre 2014 ISSN: 0014-1496, eISSN: 1988-8546, doi: 10.3989/estgeogr.201419 
En estas imágenes se observa la evolución de los suelos sellados entre 1989 y 2011. Estos suelos tienen tonos muy claros y los más blancos corresponden a las naves industriales, infraestructuras viarias y nuevas urbanizaciones. Las urbanizaciones no finalizadas sólo muestran la estructura enrejada propia de la red viaria.

Con la imagen Spot pancromática se obtiene una mayor precisión en la interpretación visual; resalta claramente el patrón espacial por sus formas geométricas (calles, rotondas, edificios en construcción, parcelas roturadas, etc.) y tonos muy claros en todas las áreas selladas. Se han seleccionado tres sectores que tratan de recoger diferentes tipologías de sellado (figura 3). La primera se refiere a urbanizaciones o residencias secundarias bien integradas en el paisaje con amplias superficies arboladas, en las que resulta difícil la delimitación de las edificaciones (urbanización de Sotolargo en el municipio de Valdeaveruelo); el segundo tipo acoge un núcleo rural compacto (Chiloeches), que ha experimentado un fuerte crecimiento en el municipio con nuevas urbanizaciones en su entorno, unas ya finalizadas y otras «fantasmas»; en esta imagen pueden compararse los diferentes patrones espaciales del sellado de suelos. La tercera tipología se centra en una ciudad media (Guadalajara) y sus alrededores, en donde se discriminan con claridad las edificaciones antiguas de la ciudad, nuevas urbanizaciones periféricas y naves industriales.

La menor resolución espacial de las bandas multiespectrales del satélite Spot frente a la banda pancromática no resulta muy adecuada para la identificación visual del sellado. Esta deficiencia se mejora mediante la mezcla de todas las imágenes SPOT, de modo que se obtiene la mayor resolución espacial de la banda pancromática y la resolución multiespectral. La imagen fusionada sí permite identificar muy bien las diferentes tipologías de sellado, especialmente las construcciones sin finalizar, que destacan por su alta reflectividad. No obstante, para una mejor identificación del sellado es aconsejable recurrir también a los sensores con mayor resolución espectral que permitan discriminar algunas superficies selladas mediante alguna mejora espectral. De todas ellas, en las imágenes Landsat la que ofrece mejores resultados es la mejora obtenida mediante componentes principales, de los que el segundo componente es el que discrimina con precisión los diferentes patrones urbanos, industriales e infraestructuras viarias (figura 4).

Por el contrario, otras mejoras espectrales como la transformación de IHS a RVA o viceversa sólo discriminan los suelos desprovistos de vegetación siendo necesario diferenciar por su patrón espacial los suelos desnudos (sin cultivos) de los urbanizados. Tampoco el Índice de la Diferencia Normalizada de Vege- 


\section{FIGURA 3}

IMÁGENES SPOT DEL 17-09-2011. TIPOLOGÍA DE SELLADO DE SUELOS
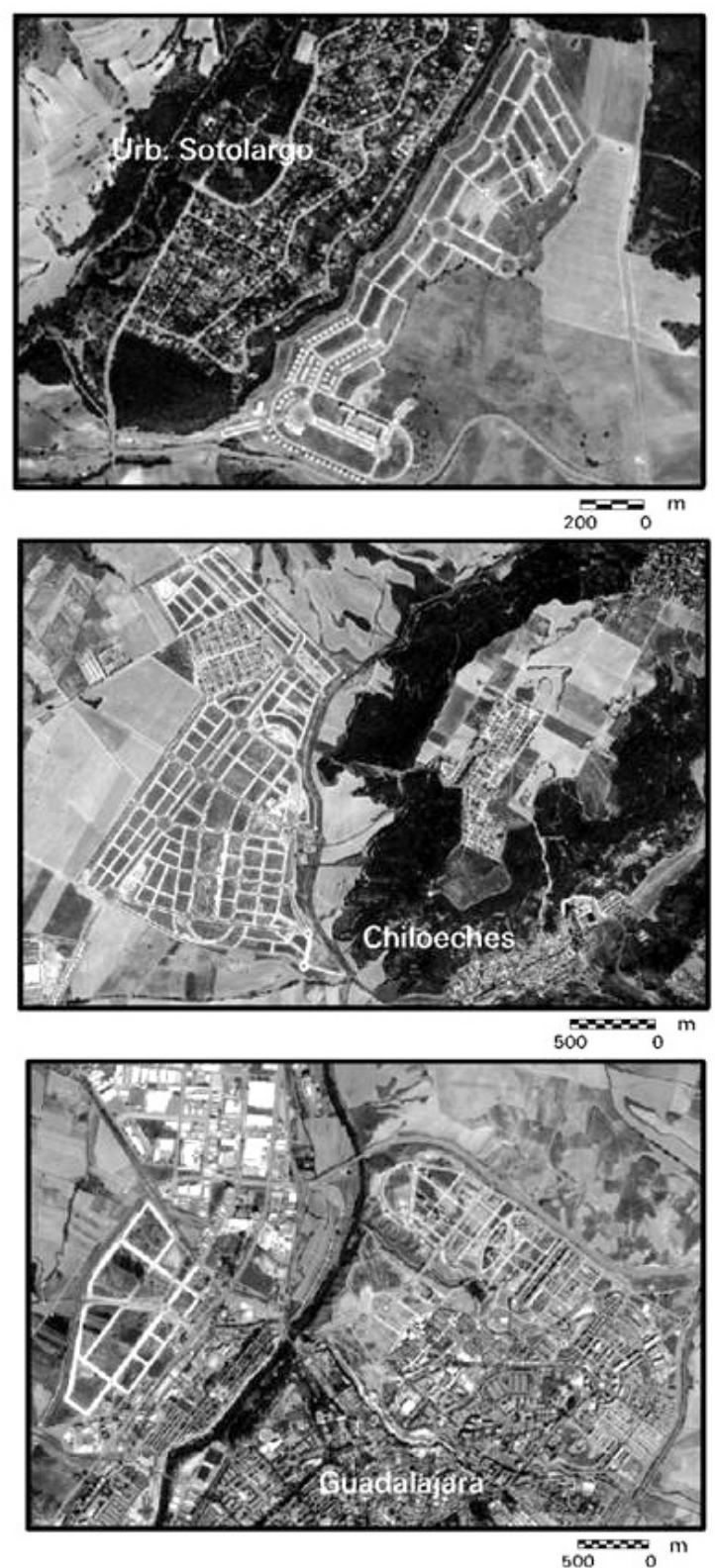

Estudios Geográficos, Vol. LXXV, 277, pp. 597-618, julio-diciembre 2014 ISSN: 0014-1496, eISSN: 1988-8546, doi: 10.3989/estgeogr.201419 
FIGURA 4

SEGUNDO COMPONTE PRINCIPAL DE LAS IMÁGENES LANDSAT ENTRE 1989 Y 2011. EN NEGRO LOS SUELOS SELLADOS
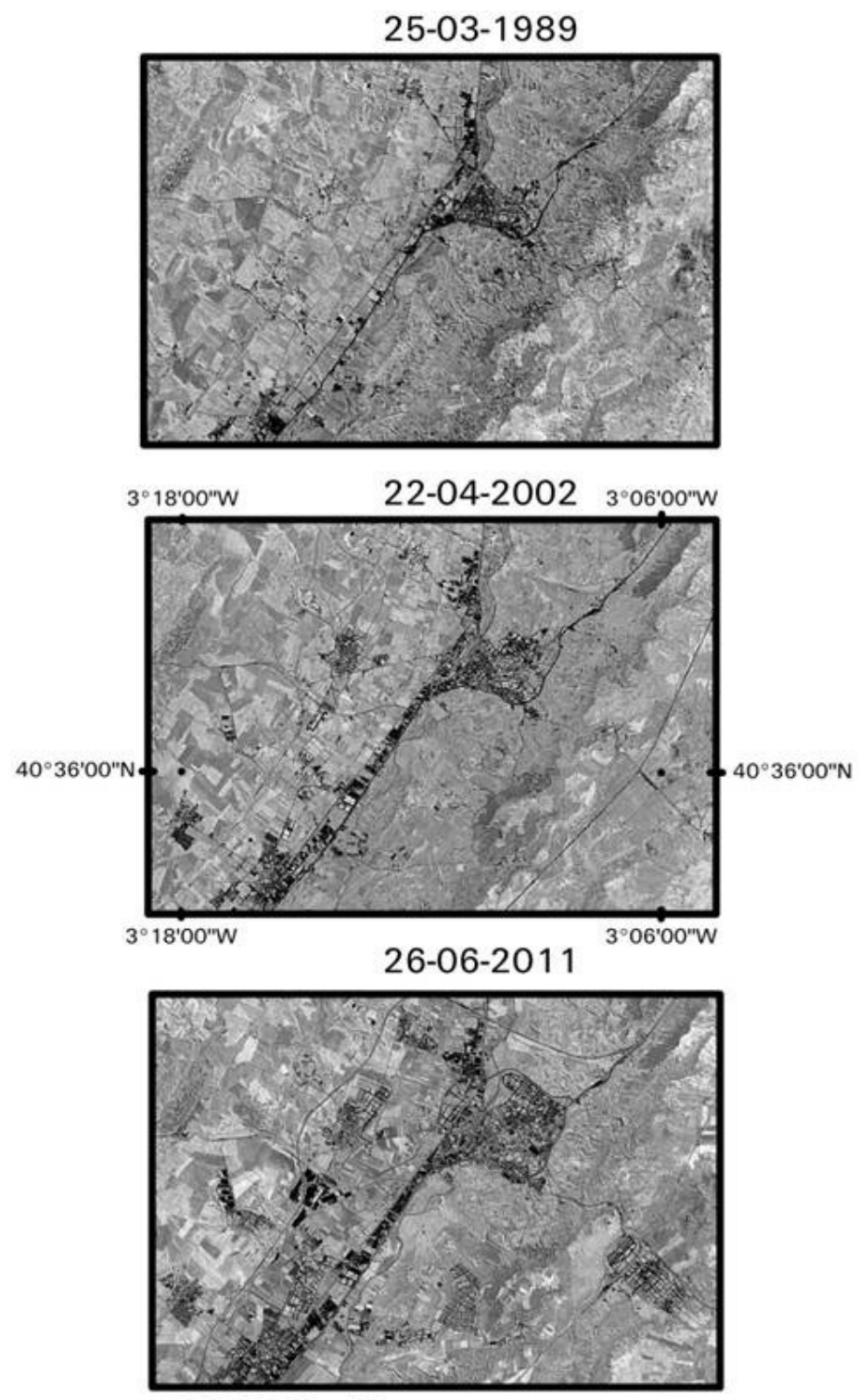

$\mathrm{E}=\mathrm{E}=\mathrm{km}$

Estudios Geográficos, Vol. LXXV, 277, pp. 597-618, julio-diciembre 2014 ISSN: 0014-1496, eISSN: 1988-8546, doi: 10.3989/estgeogr.201419 
tación, ni el Tasseled Cap ofrecen buena discriminación, a diferencia de los resultados obtenidos por otros autores en áreas próximas (Sánchez et al., 2009). Esto puede ser debido a las fechas utilizadas; los meses y años con mucha cobertura vegetal (marzo de 1989 y abril de 2002) las urbanizaciones con amplios jardines son difíciles de distinguir y, en épocas más secas (junio de 2011), el NDVI no resulta útil en áreas con predominio de suelos erosionados, secos y claros, si bien sí es posible diferenciar los grandes polígonos industriales. En cuanto a mejoras espaciales la que ofrece mejor discriminación es la obtenida aplicando un filtro realizado mediante el algoritmo de convolución con la suma de $5 \times 5$.

El análisis multitemporal de las imágenes se ha realizado mediante la detección de cambios de las imágenes de los componentes principales entre 1989 y 2011. Se han resaltado las diferencias digitales superiores al 70\%, de forma que la nueva imagen obtenida resume en color negro los suelos sellados entre ambas fechas (figura 5).

\section{FIGURA 5}

DETECCIÓN DE CAMBIOS ENTRE 1989 Y 2011. EN NEGRO EL INCREMENTO DE LOS SUELOS SELLADOS

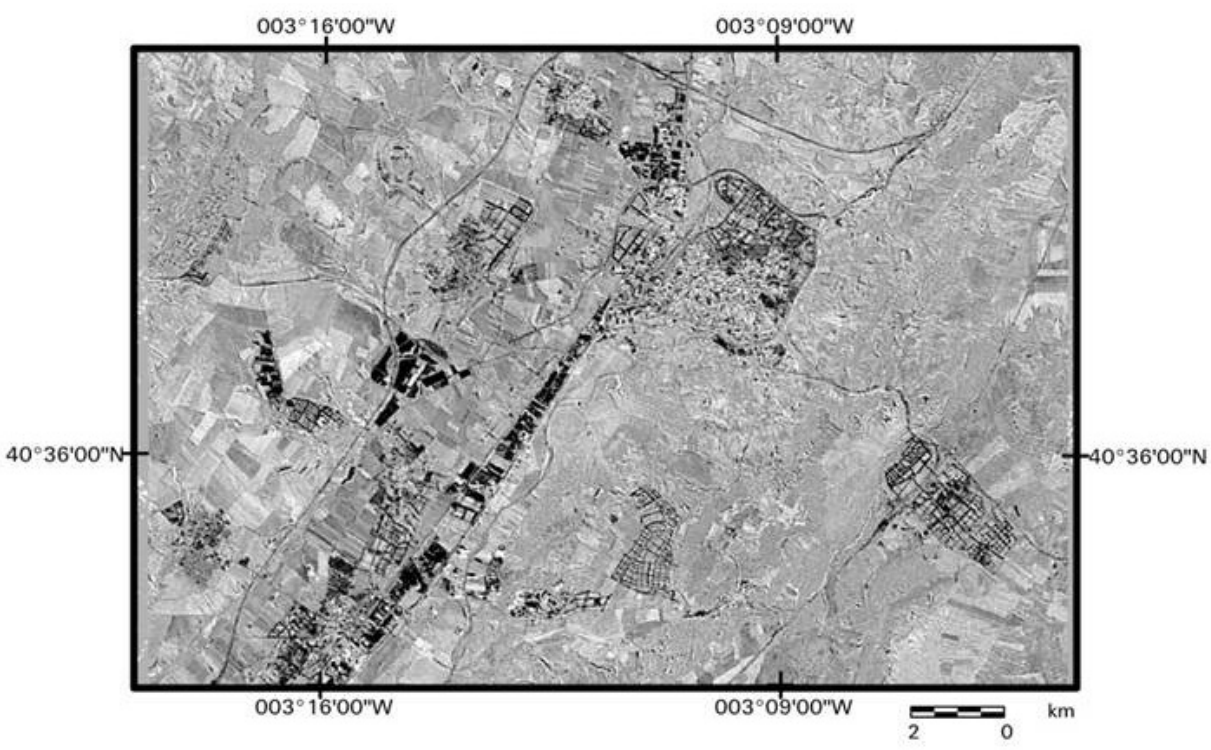




\section{Clasificación supervisada y análisis de los suelos sellados}

Dado que las imágenes en componentes principales son las que han obtenido una mejor discriminación del sellado son las utilizadas para realizar las clasificaciones supervisadas. Mediante estas clasificaciones se obtiene la superficie sellada del corredor del Henares y su entorno para las tres fechas analizadas 1989, 2002 y 2011, (tabla 3).

Las diferentes superficies selladas para fechas muy similares responden a la distinta resolución espacial de los dos satélites utilizados, siendo mayor la superficie estimada en las imágenes Landsat, de menor resolución espacial y, por tanto, menor precisión. El porcentaje estimado de sellado de suelo es más fiable en las imágenes Spot, pues su mayor resolución espacial permite obtener muestras de las superficies selladas más precisas para la clasificación. Por ello, a las superficies obtenidas mediante las clasificaciones de las imágenes Landsat se le aplica un factor de corrección del 0,75. Diferentes autores han utilizado factores de corrección en estudios multitemporales basados en imágenes de distinta resolución espacial (Zhang, 2001; Coppin et al., 2004; Lu et al., 2008).

Durante los 22 años transcurridos entre 1989 y 2011 se ha incrementado el sellado en torno al $6 \%$.

Las áreas más conflictivas para determinar el sellado son las urbanizaciones abiertas, con amplios espacios de vegetación natural. En el espacio analizado un ejemplo representativo se observa en la urbanización de Sotolargo, en la que el bosque de encinas y el sotobosque de jaras y romeros está mezclado con las viviendas unifamiliares, lo que impide delimitar con precisión la superficie real de suelos sellados (fig. 3). En estos tipos de urbanizaciones, principalmente destinadas a residencias secundarias, la evaluación de la pérdida de suelo hay que realizarla a partir de fotografías o imágenes de gran resolución espacial o técnicas de análisis espectral (Tomas et al., 2010).

TABLA 3

SUPERFICIES Y PORCENTAJE DEL SUELO SELLADO

\begin{tabular}{ccccc}
\hline Fecha & ha Selladas & Total ha imagen & \% Sellado & \% Sellado corregido \\
\hline $25 / 03 / 1989$ & 1.879 & 27.933 & 6,73 & 5,05 \\
$22 / 04 / 2002$ & 3.990 & 28.020 & 14,24 & 10,68 \\
$26 / 06 / 2011$ & 4.276 & 27.057 & 15,80 & 11,85 \\
$17 / 09 / 2011$ & 3.172 & 26.796 & 11,83 & 11,83 \\
\hline
\end{tabular}

Estudios Geográficos, Vol. LXXV, 277, pp. 597-618, julio-diciembre 2014 ISSN: 0014-1496, eISSN: 1988-8546, doi: 10.3989/estgeogr.201419 
Esta misma dificultad aparece en los mapas de ocupación del suelo SIOSE, ya que homogeniza el área sellada sin considerar si existe mezcla con otros usos (vegetación natural, pequeñas parcelas cultivadas, suelo desnudo, erial, etc.). Por lo demás, comparando la clasificación TM de 2011 con el mapa del SIOSE, existe una gran coincidencia, si bien este mapa ha quedado algo atrasado no representando muchas de las urbanizaciones más recientes.

Aún así, la cartografía y cuantificación de los suelos sellados ofrece bastante precisión en la mayor parte de tipologías (infraestructuras viarias, naves industriales, núcleos urbanos y rurales, urbanizaciones periféricas, aisladas, etc.), tanto con las imágenes Landsat como con las Spot. Las primeras, además, tienen a su favor que existe un amplio registro de imágenes desde los años ochenta, lo que facilita los estudios multitemporales. Estos buenos resultados se han confirmado, no sólo con la cartografía mencionada anteriormente, sino también con la verdad terreno. Para ello se han seleccionado diez áreas test, considerando las diferentes tipologías de sellado y asociaciones de suelos, que se han visitado en el campo para comprobar la veracidad entre la clasificación obtenida y la verdad terreno. Aunque la clasificación realizada a partir de los componentes principales alcanzó un grado de precisión con la verdad terreno del $82 \%$, con la nueva información se ha realizado un remuestreo hasta alcanzar una fiabilidad del $95 \%$.

Una vez seleccionadas las imágenes que ofrecen una mejor discriminación del sellado se evalúa cómo afecta a los distintos tipos y usos del suelo. Entre las imágenes de 1989 y 2002 se observa como el incremento del sellado afecta fundamentalmente a la vega del río Henares y las terrazas más bajas, sellando suelos de alta y media calidad agrológica, que corresponden aquí a fluvisoles y cambisoles, afectando sobre todo a parcelas dedicadas a cultivos de regadío (fig. 6). El sellado de los suelos más fértiles también se ha detectado en otras provincias españolas (Añó et al., y Varela et al., 2011), con porcentajes superiores al 10\% en la costa levantina. Entre los años 2002 y 2011 el sellado se ha desplazado a las terrazas más altas y a la superficie del páramo, actuando sobre todo en cambisoles y, en menor proporción, en luvisoles y leptosoles cálcicos y réndsicos; en estos casos han desaparecido suelos dedicados a cereales de secano. Destaca en la margen derecha del Henares el sellado de luvisoles crómicos (denominados tradicionalmente suelos rojos mediterráneos), suelos muy característicos de la región mediterránea, que han tardado más de un millón de años en formarse y que están desapareciendo en muy pocos años, sin posibilidad de una nueva evolución. Así, en la actualidad están desapareciendo suelos muy frágiles que constituían un elemento importante en los ecosistemas mediterráneos, ya que la presencia de horizontes arcillosos en 
profundidad permite a las plantas xerófitas captar agua en las épocas del año con déficit hídrico. Por ello, el uso de suelo más afectado ha sido el de viñedos y los cultivos arbóreos mediterráneos (olivos y frutales). En el techo del páramo la presencia de nuevas urbanizaciones da lugar a la desaparición de leptosoles réndsicos que, aún limitados por la poca profundidad de los horizontes edáficos, sus propiedades químicas ( $\mathrm{pH}$ básico y alto contenido en cationes de cambio) han permitido que tengan un alto rendimiento en las cosechas de cereales de secano y/o plantas aromáticas.

Las naves industriales se establecieron tradicionalmente en las proximidades del río Henares sobre cambisoles eútricos y fluvisoles. En la actualidad esta actividad se está desplazando a terrazas más altas afectando a luvisoles. La

Figura 6

CLASIFICACIÓN SUPERVISADA DE SUELOS SELLADOS EN LAS IMÁGENES TM Y ETM+ Y SUPERPOSICIÓN DEL MAPA DE SUELOS

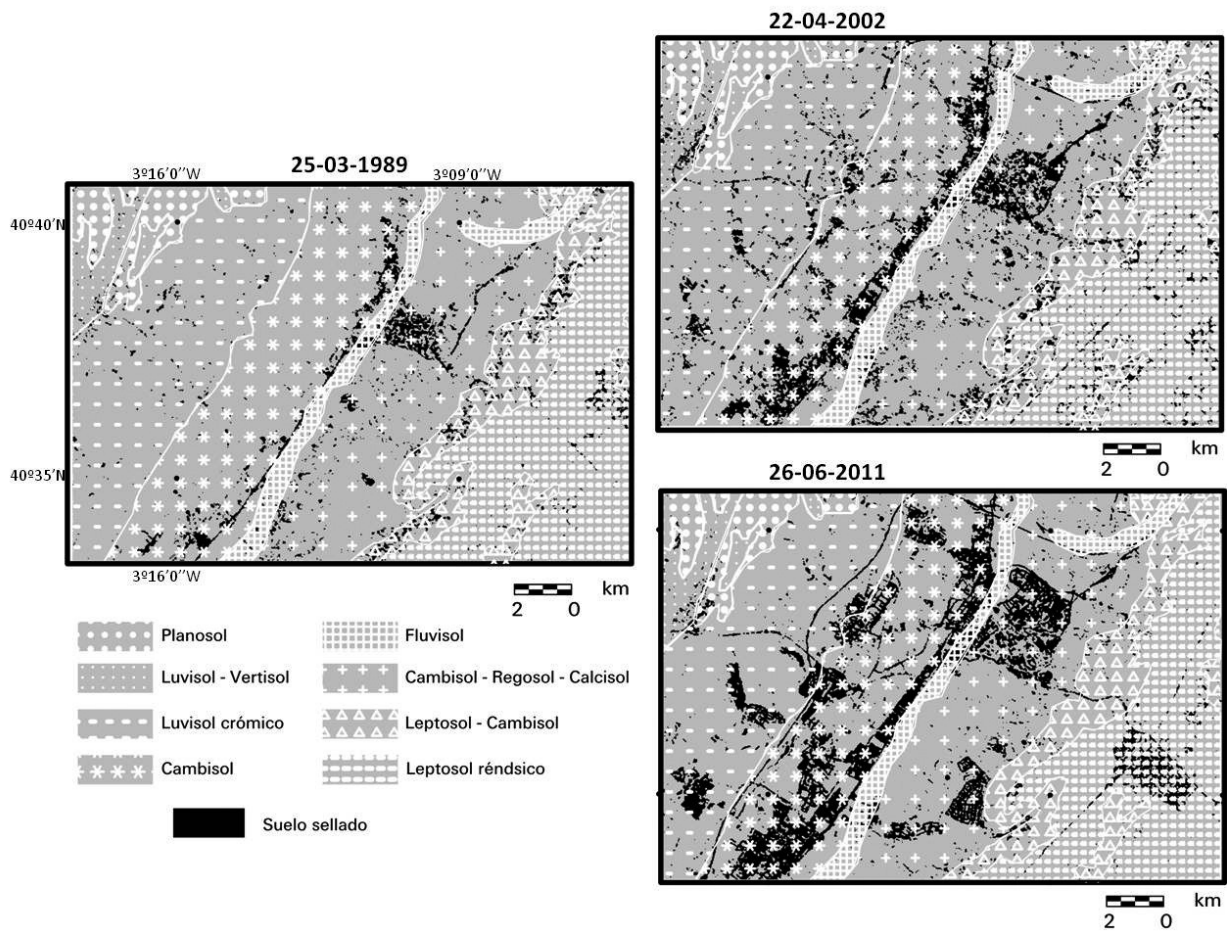

Fuente: Guerra y colab., 1970, adaptado por las autoras.

Estudios Geográficos, Vol. LXXV, 277, pp. 597-618, julio-diciembre 2014

ISSN: 0014-1496, eISSN: 1988-8546, doi: 10.3989/estgeogr.201419 
ocupación del suelo para uso residencial-urbano, que en los años ochenta ocupaba cambisoles, regosoles y calcisoles, se ha extendido a todos los suelos, con especial desarrollo en este siglo en luvisoles y leptosoles, donde se asientan las urbanizaciones sin finalizar. El cambio más importante en las infraestructuras es debido a la autopista de peaje R2 y a las vías del AVE. Ambas tienen un gran impacto visual y llevan asociado un importante sellado debido a la construcción de urbanizaciones en su entorno.

\section{CONCLUSIONES}

La incorporación de la teledetección a la evaluación y seguimiento del sellado del suelo permite la actualización casi constante y una fiabilidad elevada.

La imagen Spot pancromática fusionada con la multiespectral ofrece una gran precisión para establecer una tipología de sellado de suelos: urbano, industrial, residencial e infraestructuras. Las imágenes Landsat, con menor resolución espacial llevan a una sobredimensión del sellado en algunas áreas residenciales con amplios espacios verdes. En estas imágenes las combinaciones de bandas más adecuadas para identificar el sellado de suelos son las obtenidas con los infrarrojos medios y visibles (5-2-1, 7-2-1, 1-1-5, 3-2-1 y 7-5-1 en R-V-A). No así con el infrarrojo próximo, que sólo destaca la vegetación y enmascara algunos suelos urbanizados. De todas las combinaciones de bandas la visualización óptima del sellado se obtiene con la mezcla del canal azul del visible (asignándole dos cañones de color) y el infrarrojo próximo, ya que resalta la humedad (o ausencia de ella) y la impermeabilización del suelo.

En el corredor del Henares y su entorno el sellado entre 1989 y 2011 se ha incrementado en torno al $6 \%$ en detrimento de cultivos de regadío y secano.

En el siglo pasado el sellado de suelos ha afectado principalmente a asociaciones de cambisoles y fluvisoles situados en la vega del río o en las terrazas más bajas. Si bien son los suelos más fértiles, no requieren muchos años para su formación. Pero en el siglo actual el sellado se ha desplazado a terrazas más altas, sellando de forma irreversible suelos muy antiguos (luvisoles crómicos). Por tanto, una de las consecuencias más graves del sellado en el área de estudio es la desaparición de suelos frágiles que, a lo largo de miles de años, habían alcanzado un equilibrio con otros elementos del ecosistema.

La desaparición de suelos en la llanura de inundación y terrazas bajas introduce importantes cambios en el balance de agua, incrementando los problemas de hidromorfismo y de escorrentía superficial. 
La cartografía convencional utilizada en múltiples trabajos, se queda atrasada rápidamente en procesos que cambian a mucha velocidad. Poder cartografiar el sellado directamente en las imágenes de satélite permite una cartografía siempre actualizada.

Fecha de recepción: 27 de febrero de 2013.

Fecha de aceptación: 27 de septiembre de 2013.

\section{BibLiografíA}

AEMA, (2006): Urban sprawl in Europe - The ignored chalenge. Informe de la Agencia Europea de Medio Ambiente, octubre de 2006.

Añó Vidal, C.; Pascual Aguilar, J. A. y Sánchez Díaz (2005): "Capacidad de uso agrícola y sellado antropogénico del suelo en la franja litoral de la provincia de Castellón”. Investigaciones Geográficas, 38, pp. 65-77.

Bruinsma, F. \& Rietveld, P. (1993): "Urban Agglomerations in European Infrastructure Networks". Urban Studies, 30/6, pp. 919-934.

Blum, W. E. H. (1998): "Soil degradation caused by urbanization and industrial", en H. P. Blume, H. Eger, E. Fleischhaver, A. Hebel, C. Reij y K. G. Steinen (eds.): Towards Sustainable land use: furthering cooperation between people and institution. Reiskirchen, Germany, Catena Verlag, pp. 755-766. Advances in Geoecology, 31.

Blum, W. E. H.; Büsing, J. y Montanarella, L. (2004): "Research needs in support of the European thematic strategy for soil protection". TrAC Trends in Analytical Chemistry, 23/10-11, pp. 680-685.

Castillo, V.; Vandekerckhove, L. y Jarman, R. (2004): Working Group on Soil Erosion Introduction. Final report, European Commision, 23 pp.

Catalá Mateo, R.; Bosque Sendra, J. y Plata Rocha, W. (2008): "Análisis de posibles errores en la base de datos Corine Land Cover (1990-2000) en la Comunidad de Madrid." Estudios Geográficos, LXIX/264, pp. 81-104.

Chuvieco, E. (2000): Fundamentos de Teledetección espacial. Madrid, Ed. Rialp, 568 pp.

Comisión Europea (2012): Documento de trabajo de los servicios de la comisión. Directrices sobre mejores prácticas para limitar, mitigar o compensar el sellado del suelo. Bruselas, 15.5.2012, SWD, pp. 101 final/2.

Coppin, P.; Jonckheere, I.; Nackaerts K.; Muys B. y Lambin E. (2004): "Digital change detection methods in ecosystem monitoring: A review." International Journal of Remote Sensing, 25, pp. 1565-1596.

Effland, W. R. y Pouyat, R. V. (1997): "The genesis, classification, and mapping of soils in urban areas". Urban Ecosyst. 1, pp. 217-228.

Escudero, R.; Sánchez, B. y Moral, F. (2010): El proyecto GMES de sellado de suelo como ejemplo de una forma distribuida y colaborativa de abordar proyectos europeos de tele- 
detección. Congreso Nacional de Medio Ambiente, Conama10, Madrid, Ed. Conama.

Estébanez, J. (1980): "Esquema interpretativo del proceso de urbanización del medio rural madrileño". Boletín de la Real Sociedad Geográfica, CXVI, pp. 101-127.

Feria Toribio, J. M. (2004): "Problemas de definición de las áreas metropolitanas en España". Boletín de la AGE, 38, pp. 85-99.

García Rodríguez, Ma P. y Pérez González, M. E. (2007): "Changes in soil sealing in Guadalajara (Spain): cartography with Landsat images". Science of the Total Environment 378/1-2, pp. 209-213.

García Rodríguez, Ma P. y Pérez González, M. E. (2011): "Sellado de fluvisoles en la Comunidad de Madrid. Análisis a partir de imágenes Lansdsat". Anales de Geografía de la Universidad Complutense, 31/2, pp. 125-137.

Guerra, A.; Monturiol, F; Bodorrey, T.; De la Horra, J. L.; Labrandero, J. L. y Carlevaris, J. J. (1970): Mapa de suelos de la provincia de Guadalajara, escala 1: 250.000. Madrid, CSIC.

Helliwell J. F. \& Verdier, G. (2001): "Measuring internal trade distances: a new method applied to estimate provincial border effects in Canada". The Canadian Journal of Economics, 34/ 4, pp. 1024-1041.

Kampouraki, M.; Wood, G. y Brewer, T. (2006): "The application of remote sensing to identify and measure sealed areas in urban environments", en: Proceeding from ISPRS 1st International Conference on Object-based Image Analysis. Saltzberg, Austria, Editor(s): S. Lang, T. Blaschke, E. Schöpfer.

Lavalle, C.; Demicheli, L.; Kasanko, M.; Turchini M.; Niederhuber M. y McCormick N. (2001): Murbandy/Moland Technical Report. Brussels, European Commission Euro-Report.

Lu, D.; Batistella, M.; De Miranda, EE. y Moran, E. (2008): "A Comparative Study of Landsat TM and SPOT HRG Images for Vegetation Classification in the Brazilian Amazon". Photogramm Eng Remote Sensing, 74/3, pp. 311-321.

Méndez, R. y Razquin, J. (1992): "Ciclo urbano y difusión del crecimiento en la Comunidad de Madrid", Anales de Geografía de la Universidad Complutense, 12, pp. 333-344.

Moeller, M. (2005): "Remote Sensing for the monitoring of urban growth patterns", en: Proc. of the ISPRS Joint Conference URBAN/URS. AZ, USA, Tempe,

Montanarella L. (2007): "Trends in land degradation in Europe", in: Climate and land degradation. Germany, Springer-Heidelberg, Sivakumar MVK, Ndegwa N, Edit., pp. 83-104.

Moreira, J. M. (2012): "Urbanismo expansivo: de la utopía a la realidad. Reflexiones desde la información ambiental", en V. Gozálvez Pérez, y J. A. Marco Molina, (coord.): Geografía: Retos ambientales y territoriales, Alicante, AGE, pp. 125-164.

Nizeyimana, E. L.; Petersen, G. W.; Imhoff, M. L.; Sinclair Jr., H. R.; Waltman, S. W.; Reed-Margetan, D. S.; Levine, E. R. y Russo, J. M. (2001): "Assessing the impact of land conversion to urban use on soils with different productivity levels in the USA". Soil Sci. Soc. Am. Journal, 65, pp. 391-402. 
Ridd, M. K. (1995): "Exploring a V-I-S (vegetation —impervious surface- soil) model for urban ecosystem analysis through remote sensing: comparative anatomy for cities". International Journal of Remote Sensing, 16, pp. 2165-2185.

Sánchez, B.; Moral, F; González, A. y Escudero, R. (2009): "Proyecto FTS Soil Sealing (Sellado del suelo) en España y Portugal", en: XIII Congreso Nacional de Teledetección. Calatayud, Compobell, S. L., pp. 245-248.

Scalenghe, R. y Ajmone-Marsan, F. (2009): "The anthopogenic sealing of soils in urban areas". Landscape and Urban Planning, 90/1-2, pp. 1-10.

Solís Trapero, E. (2008): "El horizonte urbano madrileño: más allá de la región políticoadministrativa". Anales de Geografía de la Universidad Complutense, 28/1, pp. 133-162.

Spies, J. (2010): "Network and border effects: Where do foreign multinationals locate in Germany?" Regional Science and Urban Economics, 40/1, pp. 20-32.

Tomas, A.; Salas, F. J.; Santos, C.; Garzón, A. y Moreno, V. (2010): "Estimación del sellado del suelo mediante técnicas de análisis espectral". Serie Geográfica, 16, pp. 81-92.

Van Camp, L.; Bujarrabal, B.; Gentile, A. R.; Jones, R.; Montanarella, L.; Olazábal, C. y Selvaradjon, S. K. (2004): Reports of the technical working groups. Established under the thematic strategy for soil protection. EUR 21319 EN/6 872. Office for Official Publ. Of the European Communities. vol. VI, Luxembourg.

Valera Lozano, A.; Añó Vidal, C. y Sánchez Díaz, J. (2011a): "Crecimiento urbano (1956-2005) y sellado antropogénico del suelo en el municipio de Alacant". Serie Geográfica, 17, pp. 97-08.

Valera Lozano, A.; Añó Vidal, C. y Sánchez Díaz, J. (2011b): “Cincuenta años (19562006) de crecimiento urbano y degradación de suelos por sellado antropogénico en el término municipal de Valencia”. Anales de Geografía de la Universidad Complutense de Madrid, 31/2, pp. 177-191.

ISRIC/FAO (2007): World Reference Base for Soil resources. World Soil Resources reports, 103.

Wu, C. (2004): "Normalized spectral mixture analysis for monitoring urban composition using ETM+ imagery”. Remote Sensing of Environment, 93, pp. 480-492.

Zhang, Y. (2001): "Detection of urban housing development by fusing multisensor satellite data and performing spatial feature post-classification". International Journal of Remote Sensing, 22/17, pp. 3339-3355.

\section{PÁGINAS WEB}

http://glcf.umd.edu/ (Fecha de consulta 28/10/2014)

http://www.ign.es (Fecha de consulta 27/10/2014)

http://www.ine.es/ (Fecha de consulta 27/10/2014)

ftp://ftp.pnt.ign.es/ (Fecha de consulta 28/10/2014)

http://earth.google.com (Fecha de consulta 27/10/2014)

http://www.eeb.org/ (Fecha de consulta 27/10/2014) 


\section{RESUMEN}

El objetivo del estudio es conocer la evolución del sellado del suelo en un área con alta presión antrópica afectada por el "efecto frontera" debido a su proximidad a una gran ciudad. Es importante analizar el tipo y calidad del suelo que está siendo afectado por este proceso. Para ello se utilizan imágenes de los sensores TM y ETM+ de los satélites Landsat e imágenes del satélite Spot seleccionando aquellos tratamientos que permiten una mejor discriminación de los suelos degradados. El sellado del suelo entre 1989 y 2002 afecta fundamentalmente a la vega del río Henares y las terrazas más bajas, impermeabilizando suelos de alta y media calidad agrológica, que corresponden aquí a fluvisoles y cambisoles. Entre los años 2002 y 2011 el sellado se desplaza a las terrazas más altas y a la superficie del páramo, actuando sobre todo en cambisoles y, en menor proporción, en luvisoles cálcicos y réndsicos y leptosoles. Por tanto, en el corredor del Henares y su entorno el sellado entre 1989 y 2011 se ha incrementado en torno al $6 \%$ en detrimento de cultivos de regadío y secano.

Palabras Clave: sellado; suelo; teledetección; urbanismo expansivo; efecto frontera.

\section{AbSTRaCt}

The aim of this study is to analyze the evolution of soil sealing in an area with high human pressure affected by the "border effect" of proximity to a big city. It is also important to analyze the type and quality of the soil that is affected by this process. We have used Landsat (TM and ETM+) and Spot satellite images, selecting those treatments that allow better discrimination of degraded soils. Soil sealing between 1989 and 2002 mainly affected the Henares River valley and the lower terraces, waterproofing soils of high and medium agricultural quality, corresponding here to fluvisoles and cambisols. Between 2002 and 2011, the sealing of soils moved to higher terraces and the surface of the plain, especially affecting cambisols and, to a lesser extent, calcic and rendsic luvisols and leptosols. Thus, in the Henares Corredor region soil sealing between 1989 and 2011 increased by 6\%, at the expense of irrigated and rainfed crops. The affected soils are luvisols, cambisols, fluvisols and leptosols.

KEY WORDS: sealing soil; remote sensing; urban sprawl; border effect.

\section{RÉSUMÉ}

Le but de cette étude est de déterminer l'évolution de l'imperméabilisation des sols dans une région avec une pression anthropique élevée et touchée par "l'effet frontière » en raison de la proximité d'une grande ville. Il est important d'analyser le type et la qualité du sol affecté par ce processus. Pour cela, les images des senseurs TM et ETM+ des satellites Landsat sont employées, ainsi que les images du satellite Spot, en sélectionnant les traitements qui permettent une meilleure discrimination des sols dégradés. Limperméabilisation des sols entre 1989 et 2002 affecte principalement la vallée de l'Henares et les terrasses inférieures. Les sols agricoles de haute et de moyenne qualité sont les plus concernés, correspondant dans ce cas à des fluvisols et des cam- 
bisols. Entre 2002 et 2011, l'imperméabilisation se déplace aux terrasses supérieures et à la surface du plateau, agissant surtout sur les cambisols et, dans une moindre mesure, sur les luvisols calciques et rendsiques et les leptosols. Ainsi, dans le Corredor del Henares, l'imperméabilisation des sols a augmenté de 6\% entre 1989 et 2011, au détriment des cultures irriguées et pluviales. Les sols concernés sont des luvisols, des cambisols, des fluvisols et des leptosols.

MoTS CLÉs: imperméabilisation; sols; télédétection; urbanisme expansif; effet frontière. 